Document downloaded from:

http://hdl.handle.net/10251/149958

This paper must be cited as:

Fraga-Timiraos, AB.; Francés-Monerris, A.; Rodríguez Muñiz, GM.; Navarrete-Miguel, M.; Miranda Alonso, MÁ.; Roca Sanjuan, D.; Lhiaubet, VL. (2018). Experimental and Theoretical Study on the Cycloreversion of a Nucleobase-Derived Azetidine by Photoinduced Electron Transfer. Chemistry - A European Journal. 24(57):15346-15354.

https://doi.org/10.1002/chem.201803298

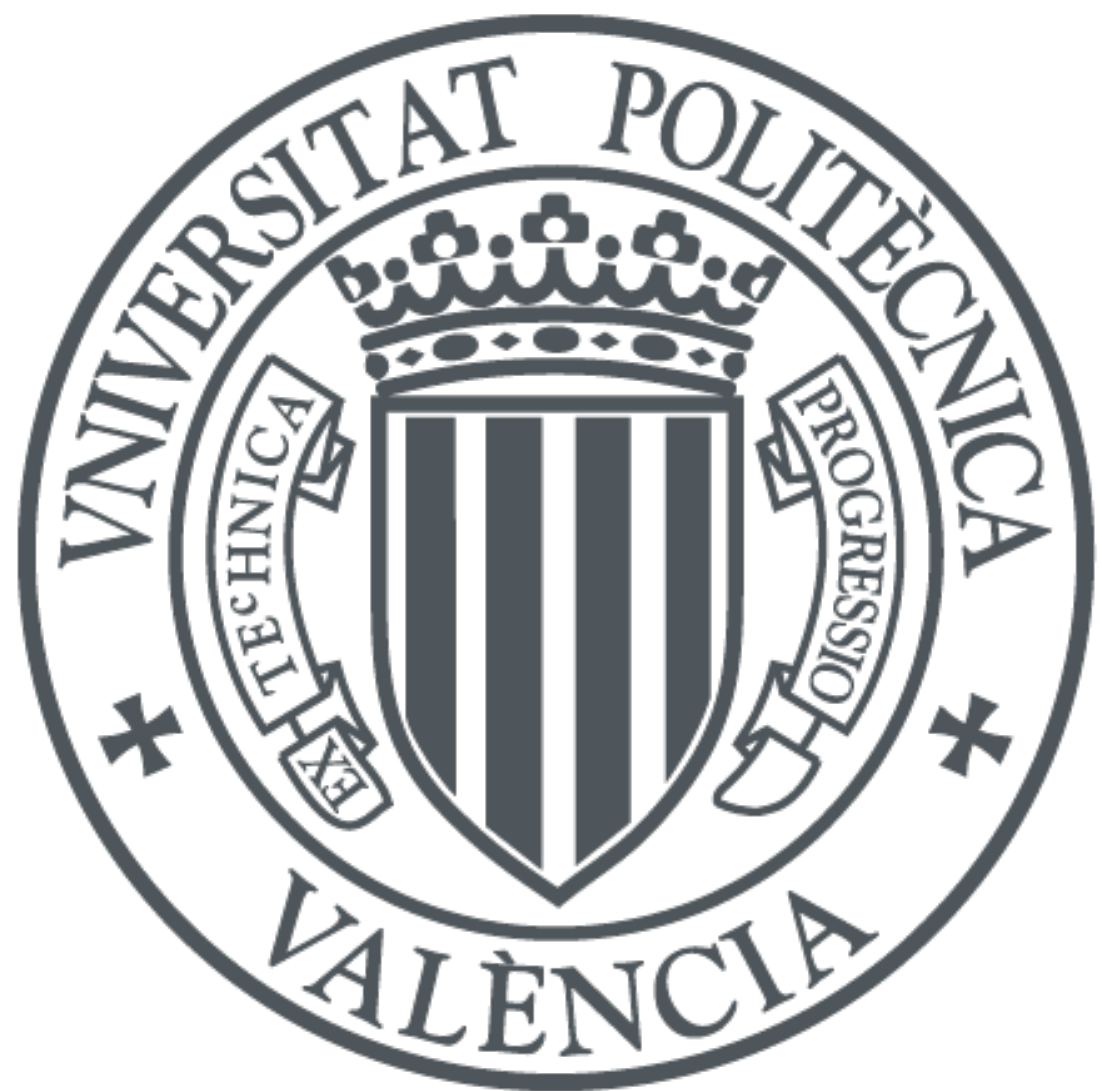

The final publication is available at

https://doi.org/10.1002/chem.201803298

Copyright John Wiley \& Sons

Additional Information 


\section{CHEMISTRY A European Journal}

\section{Accepted Article}

Title: Experimental and Theoretical Study on the Cycloreversion of a Nucleobase-Derived Azetidine by Photoinduced Electron Transfer

Authors: Ana B. Fraga-Timiraos, Antonio Francés-Monerris, Gemma M. Rodríguez-Muñiz, Miriam Navarrete-Miguel, Miguel A. Miranda, Daniel Roca-Sanjuán, and Virginie Lhiaubet-Vallet

This manuscript has been accepted after peer review and appears as an Accepted Article online prior to editing, proofing, and formal publication of the final Version of Record (VoR). This work is currently citable by using the Digital Object Identifier (DOI) given below. The VoR will be published online in Early View as soon as possible and may be different to this Accepted Article as a result of editing. Readers should obtain the VoR from the journal website shown below when it is published to ensure accuracy of information. The authors are responsible for the content of this Accepted Article.

To be cited as: Chem. Eur. J. 10.1002/chem.201803298

Link to VoR: http://dx.doi.org/10.1002/chem.201803298 


\title{
Experimental and Theoretical Study on the Cycloreversion of a Nucleobase-Derived Azetidine by Photoinduced Electron Transfer
}

\author{
Ana B. Fraga-Timiraos ${ }^{+}$, ${ }^{[a]}$ Antonio Francés-Monerris ${ }^{+},{ }^{[b]}$ Gemma M. Rodríguez-Muñiz, ${ }^{[a]}$ Miriam \\ Navarrete-Miguel, ${ }^{[c]}$ Miguel A. Miranda, ${ }^{[a]}$ Daniel Roca-Sanjuán ${ }^{\star[c]}$ and Virginie Lhiaubet-Vallet*[a]
}

\begin{abstract}
Azetidines are interesting compounds in medicine and chemistry as bioactive scaffolds but also as synthetic intermediates. However, the photochemical processes involved in the generation and fate of azetidine-derived radical ions have been scarcely reported. In this context, the photoreduction of this four-membered heterocycle might be relevant in connection with DNA (6-4) photoproduct by photolyase. Here, a stable azabipyrimidinic azetidine $A Z T_{m}$, obtained from cycloaddition between thymine and 6-azauracil units, is considered as an interesting model of the proposed azetidine-like intermediate. Hence, its photoreduction and photooxidation are thoroughly investigated through a multifaceted approach including spectroscopic, analytical and electrochemical studies complemented by CASPT2 and DFT theoretical calculations. It has been found that both injection and removal of an electron results in the formation of radical ions, which evolve towards the repaired thymine and azauracil units. Whereas photoreduction energetics are similar to those of the cyclobutane thymine dimers, photooxidation is clearly more favorable in the azetidine. Ring opening occurs with relatively low activation barriers $\left(<13 \mathrm{kcal} \mathrm{mol}^{-1}\right)$ and the process is clearly exergonic for the photoreduction. In general, a good correlation has been observed between the experimental results and the theoretical calculations, which has allowed a synergic understanding of the phenomenon.
\end{abstract}

\section{Introduction}

Azetidines are saturated four-membered ring compounds containing one nitrogen atom. They are interesting pharmacological units, in part due to the rigidity of their strained

[a] A.B. Fraga-Timiraos, ${ }^{+}$Dr. G. M. Rodríguez-Muñiz, Prof. Dr. M. A Miranda, Dr. V. Lhiaubet-Vallet Instituto de Tecnología Química UPV-CSIC Universitat Politècnica de València Consejo Superior de Investigaciones Científicas Avenida de los Naranjos, s/n, ES-46022 Valencia (Spain) E-mail: Ivirgini@itq.upv.es

[b] Dr. A. Francés-Monerris ${ }^{+}$

Laboratoire de Physique et Chimie Théoriques (LPCT) Université de Lorraine, CNRS F54000 Nancy (France)

[c] M. Navarrete-Miguel, Dr D. Roca-Sanjuán Instituto de Ciencia Molecular Universitat de València

P.O. Box 22085, ES-46071, Valencia (Spain) E-mail: daniel.roca@uv.es

$\left.{ }^{+}\right] \quad$ These authors contributed equally to this work.

Supporting information for this article is given via a link at the end of the document.((Please delete this text if not appropriate)) ring that offers an added value in the search for new compact scaffolds, but also in connection with their presence in natural products and their application as peptidomimetics. [1] From a synthetic point of view, their facile ring-opening by nucleophiles makes them valuable building blocks in the construction of complex nitrogen containing molecules. ${ }^{[1 c, 2]}$ Moreover, azetidines have found application as chiral auxiliaries or ligands in metalcatalyzed reactions. ${ }^{[1 \mathrm{a}, 3]}$

By contrast, the generation and fate of azetidine-derived biradicals or radical ions have been scarcely reported. ${ }^{[4]}$ In this context, direct irradiation of 1,4-diphenylazetidine yields mainly styrene and $\mathrm{N}$-phenylmethanimine through formation of a 1,4biradical and its subsequent C2-C3 cleavage. ${ }^{[4]]}$ Concerning the reactivity via radical ions, tris(4-bromophenyl)aminium radical cation triggers the oxidative ring opening of $1,2,3-$ triphenylazetidine, affording stilbene and N,1diphenylmethanimine. ${ }^{[4 b]}$ Cyanoaromatics have also been used as electron acceptors in the oxidation of a biomimetic azetidine obtained from photocycloaddition between 6-azauracil and cyclohexene. ${ }^{[4 \mathrm{~d}]}$ In comparison with azetidines, the cycloreversion of oxetanes mediated by photoinduced electron transfer has been thoroughly investigated, both experimentally and theoretically. This process occurs through a non-concerted two-step mechanism, with initial $\mathrm{C}$-O cleavage in the reductive version and a substituent dependent $\mathrm{C}-\mathrm{C}$ or $\mathrm{C}-\mathrm{O}$ cleavage in the oxidative counterpart. ${ }^{[5]}$ More importantly, photoreductive electron transfer of the oxetane and azetidine rings is of biological interest in connection with its possible involvement in DNA repair catalyzed by photolyases, which takes advantage of solar light to trigger the cycloreversion of dimeric pyrimidine lesions through electron transfer from an excited flavin cofactor. Interestingly, the mechanism involved in the repair of the (6-4) photoproducts by these enzymes is still under debate. ${ }^{[6]}$ For a longtime, it was proposed that an oxetane or azetidine-like intermediate is involved in the catalytic cycle for dimers having a thymine or a cytosine at the $3^{\prime}$ end, respectively. ${ }^{[7]}$ This hypothesis has been challenged during the last decade, ${ }^{[6 a, 6 b]}$ but recent spectroscopic studies are consistent with the formation of a reversible intermediate that might be in line with the involvement of a saturated heterocyclic intermediate. ${ }^{[6 \mathrm{~d}, 8]}$

In a previous communication, the photoinduced reductive cycloreversion of an azetidine derivative has been reported for the first time. ${ }^{[4 c]}$ This was achieved by using a stable azabipyrimidinic azetidine $\left(A Z T_{m}\right.$, Scheme 1) as model for the short-lived intermediate proposed for the repair of (6-4) photoproducts at TC sequences. Here, the photoreductive process, together with its photooxidative version, has been thoroughly investigated through a multifaceted approach including spectroscopic, analytical and 
electrochemical investigations complemented by theoretical calculations. Parallel studies on a related cyclobutane derivative $\left(\mathrm{T}_{\mathrm{m}}<>\mathrm{T}_{\mathrm{m}}\right.$, Scheme 1) are also included for comparison.

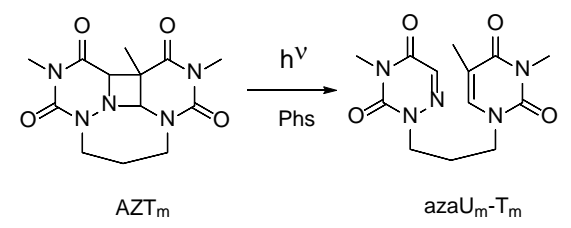

$$
\text { Tmerme }
$$

Scheme 1. Photocycloreversion of the azabipyrimidinic $A Z T_{m}$ model in the presence of a photosensitizer (Phs) and structure of the cyclobutane dimer $\mathrm{T}_{\mathrm{m}}<>\mathrm{T}_{\mathrm{m}}$.

\section{Results and Discussion}

The obtained results are presented below, structured under differents sub-headings dealing with excited states dynamics, electrochemical behavior, photocycloreversion, quantum chemistry determination of the photoreductive and photooxidative properties, and decomposition mechanisms of AZT radical cation and anion.

\section{Excited states dynamics}

In a first stage, the electron transfer process was studied by steady-state (SS) and time-resolved (TR) fluorescence. Thus, acetonitrile solutions of the selected photosensitizers (Phs) were prepared, and their emission spectra were registered in the absence and in the presence of increasing amounts of the cyclobutane $\left(T_{m}<>T_{m}\right)$ or azetidine ( $\left.A Z T_{m}\right)$ compounds, used as quenchers. The selected sensitizers (see Chart 1) were 1methoxynaphthalene (1-MN) and chrysene (CHRY) as the electron donating compounds (reduction potential in the singlet excited state $\mathrm{E}^{\star}$ ca. -2.5 and $-2.1 \mathrm{~V}$ vs $\mathrm{Ag} / \mathrm{AgCl}$, respectively), together with 1,4-dicyanonaphthalene $\left(\mathrm{DCN}, \mathrm{E}^{*}=2.4 \mathrm{~V}\right.$ vs $\mathrm{Ag} / \mathrm{AgCl}$ ) and 9,10-dicyanoanthracene (DCA, $E^{*}=1.8 \mathrm{~V}$ vs $\mathrm{Ag} / \mathrm{AgCl}$ ) for the photooxidative version.

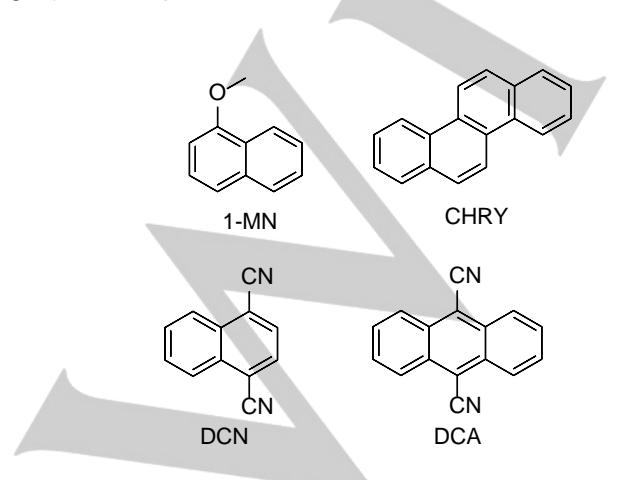

Chart 1. Structure of the selected photoreductants and photooxidants.
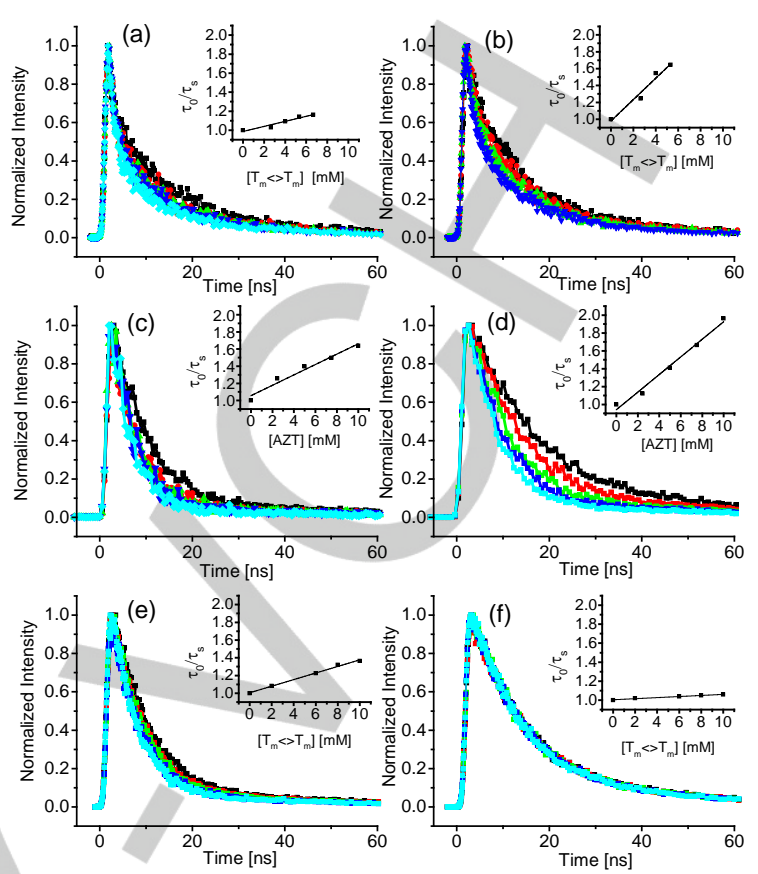

Figure 1. Fluorescence kinetic traces and their corresponding Stern-Volmer plot obtained for (a) 1-MN $\left(\lambda_{\text {exc }}=310 \mathrm{~nm}\right)$ and (b) CHRY $\left(\lambda_{\text {exc }}=310 \mathrm{~nm}\right)$ in the presence of increasing amounts of $\mathrm{T}_{\mathrm{m}}<>\mathrm{T}_{\mathrm{m}}$ (from 0 to $7 \mathrm{mM}$ ); (c) $\mathrm{DCN}\left(\lambda_{\mathrm{exc}}=310\right.$ $\mathrm{nm})$ and $(\mathrm{d}) \operatorname{DCA}\left(\lambda_{\mathrm{exc}}=375 \mathrm{~nm}\right)$ in the presence of increasing amounts of $A Z T_{m}$ (from 0 to $10 \mathrm{mM})$; (e) DCN $\left(\lambda_{\mathrm{exc}}=310 \mathrm{~nm}\right)$, (f) $\operatorname{DCA}\left(\lambda_{\mathrm{exc}}=375 \mathrm{~nm}\right)$ in the presence of increasing amounts of $\mathrm{T}_{\mathrm{m}}<>\mathrm{T}_{\mathrm{m}}$ (from 0 to $10 \mathrm{mM}$ ).

The experiments using photoreductants 1-MN and CHRY were performed using $T_{m}<>T_{m}$ as the accepting moiety and compared to those reported for $A Z T_{m}$ (Table 1). ${ }^{[4 c]}$ For the selected photooxidants DCN and DCA, new experiments were run for both $A Z T_{m}$ and $T_{m}<>T_{m}$. Fluorescence measurements revealed $a$ decrease of the emission intensity in all the photosensitizer/quencher combinations (Figure S1 of $\mathrm{SI}$ ). Bimolecular rate constants of the electron transfer process from steady-state experiments $\left(\mathrm{k}_{\mathrm{q}}(\mathrm{SS})\right)$ were determined as the slope of the regression line obtained from the Stern-Volmer plot (Material and Methods eq. 1 and Figure S1, inset), which represents the variation of the fluorescence intensity $\left(1 / \mathrm{I}_{0}\right)$ as a function of the quencher concentration. Quenching of the electron donors 1-MN and CHRY by $\mathrm{T}_{\mathrm{m}}<>\mathrm{T}_{\mathrm{m}}$ occurred with a $\mathrm{k}_{\mathrm{q}}(\mathrm{SS})$ value of 16.3 and $3.3 \times 10^{9} \mathrm{M}^{-1} \mathrm{~s}^{-1}$ (Figure S1, insets). For the process between photooxidants and $A Z T_{m}, k_{q}(S S)$ was of 72.8 and $7.0 \mathrm{x}$ $10^{9} \mathrm{M}^{-1} \mathrm{~s}^{-1}$ for DCN and DCA; lower values of 15.8 and $0.4 \times 10^{9}$ $\mathrm{M}^{-1} \mathrm{~S}^{-1}$ were determined for the DCN/T $\mathrm{m}<>\mathrm{T}_{\mathrm{m}}$ and DCA $/ \mathrm{T}_{\mathrm{m}}<>\mathrm{T}_{\mathrm{m}}$ combinations, respectively. Indeed, the rate constant for DCN/AZT $m$ was abnormally high as it is faster than the diffusion control in acetonitrile, $k_{\text {diff }}$ of ca. $1.9 \times 10^{10} \mathrm{M}^{-1} \mathrm{~s}^{-1}$. Actually, partial light absorption by the concentrated quencher occurs when the sample is excited at $310 \mathrm{~nm}$, reducing the portion of light absorbed by the photosensitizer, which results in a decrease of the emission intensity. By contrast, the longer excitation wavelength used for DCA $\left(\lambda_{\mathrm{exc}}=375 \mathrm{~nm}\right)$ should ensure a more selective excitation of the photooxidant. To overcome this drawback and to evaluate whether a dynamic quenching is taking 
place, time-resolved fluorescence studies were performed (Figure 1). For photoreductants, the initial lifetimes of 1-MN and CHRY were shortened in the presence of $T_{m}<>T_{m}$, and the bimolecular rate constants of the electron transfer process $\left(\mathrm{k}_{\mathrm{q}}(\mathrm{TR})\right.$ of ca. 4.0 and $1.7 \times 10^{9} \mathrm{M}^{-1} \mathrm{~s}^{-1}$, respectively) were determined from the slope of the regression line obtained from the Stern-Volmer plot (Figure 1 , inset). This tendency is in agreement with the redox potential of the photosensitizer in the singlet excited state that points to 1$\mathrm{MN}$ as a better reductant than CHRY. Moreover, the similar values of $k_{q}(T R)$ obtained for $A Z T_{m}$ and $T_{m}<>T_{m}$ (Table 1) is suggestive of a close value for the reduction potential of both substrates. For the photooxidation process, a bimolecular quenching rate constant of ca. $7.8 \times 10^{9} \mathrm{M}^{-1} \mathrm{~s}^{-1}$ was obtained for the quenching of DCN and DCA by $A Z T_{m}$. Interestingly, lower values $\left(\mathrm{k}_{\mathrm{q}}(\mathrm{TR})\right.$ of 3.0 and $\left.<0.5 \times 10^{9} \mathrm{M}^{-1} \mathrm{~s}^{-1}\right)$ were determined with the cyclobutane derivative as the deactivating species. This revealed a more difficult oxidation of this compound by comparison with $\mathrm{AZT}_{\mathrm{m}}$.

Table 1. Lifetime $(\tau)$ and reduction potential in the singlet excited state $\left(E^{\star}\right)$ of the selected $\mathrm{Phs}$, and bimolecular rate constant $\left(\mathrm{k}_{\mathrm{q}}\right)$ for the quenching of the Phs by $A Z T_{m}$ or $T_{m}<>T_{m}$ determined by time-resolved fluorescence (TR).

\begin{tabular}{|c|c|c|c|c|}
\hline \multirow[t]{2}{*}{ Phs } & \multirow[t]{2}{*}{$\tau / \mathrm{ns}$} & \multirow[t]{2}{*}{$\mathrm{E}^{\star} / \mathrm{V}$ vs $\mathrm{Ag} / \mathrm{AgCl}$} & \multicolumn{2}{|c|}{$\mathrm{k}_{\mathrm{q}}(\mathrm{TR}) / \times 10^{9} \mathrm{M}^{-1} \mathrm{~s}^{-1}$} \\
\hline & & & $A Z T_{m}$ & $\mathrm{~T}_{\mathrm{m}}<>\mathrm{T}_{\mathrm{m}}$ \\
\hline 1-MN & 6.2 & $-2.5^{[\mathrm{a}]}$ & $4.0^{[\mathrm{d}]}$ & 3.9 \\
\hline CHRY & 11.9 & $-2.1^{[\mathrm{b}]}$ & $1.7^{[\mathrm{d}]}$ & 1.1 \\
\hline $\mathrm{DCN}$ & 7.5 & $2.4^{[c]}$ & 7.8 & 3.0 \\
\hline DCA & 12.5 & $1.8^{[\mathrm{c}]}$ & 7.8 & $<0.5$ \\
\hline
\end{tabular}

[a] From reference ${ }^{[9]}$. [b] From reference ${ }^{[10]}$. [c] From reference ${ }^{[11]}$. [d] From reference ${ }^{[4 c]}$.

\section{Electrochemical behavior}

Electrochemical studies were performed by cyclic voltammetry using a three electrode standard configuration with glassy carbon as working electrode, platinum wire as counter electrode, and $\mathrm{Ag} / \mathrm{AgCl}$ in $3 \mathrm{M} \mathrm{NaCl}$ as reference electrode. The cyclic voltammograms obtained at a scan rate of $0.1 \mathrm{~V} \mathrm{~s}^{-1}$ are shown in Figure 2. In reduction, $A Z T_{m}$ and $T_{m}<>T_{m}$ exhibited similar behavior with a wave appearing at a potential of ca. $-2.6 \mathrm{~V} v \mathrm{~s}$ $\mathrm{Ag} / \mathrm{AgCl}$. This value is compatible with that reported for the cis, syn cyclobutane dimers of 1,3-dimethythymine. ${ }^{[12]}$ By contrast, two waves were observed in oxidation for the dyad $A Z T_{m}$, the first one with a peak potential $E_{p}(1)$ at ca. $1.34 \mathrm{~V}$ (close to the $E_{p}$ of the azetidine formed between 6 -azauracil and cyclohexene $\left.{ }^{[4 d]}\right)$ and the second one $E_{p}(2)$ at ca. $1.93 \mathrm{~V}$. This latter peak is similar to that observed for $\mathrm{azaU}_{\mathrm{m}}-\mathrm{T}_{\mathrm{m}}$ dyad (see $\mathrm{SI}$ ), which might be formed during the experiment as a product of the photooxidation process. ${ }^{[12 a]}$ Concerning, $T_{m}<>T_{m}$, a single wave was observed with an $E_{p}$ of $1.85 \mathrm{~V}$, which is in agreement with the previously reported value of $1.83 \mathrm{~V}$ (vs $\mathrm{Ag} / \mathrm{AgCl}) .{ }^{[13]}$

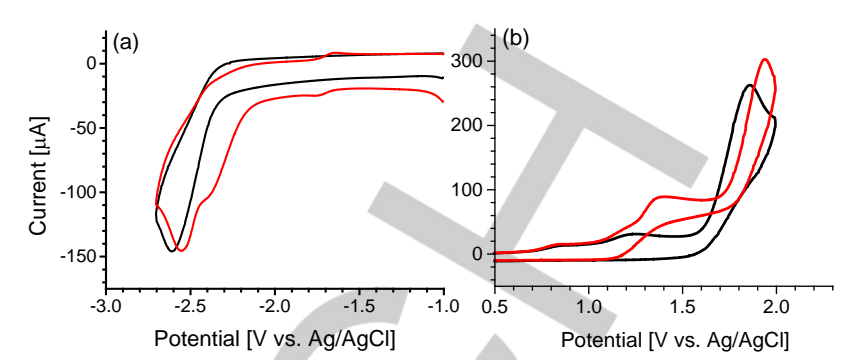

Figure 2. Cyclic voltammograms of $A Z T_{m}$ (red line, $2 \mathrm{mM}$ ) and $T_{m}<>T_{m}$ (black line, $2 \mathrm{mM}$ ) in $\mathrm{N}_{2}$-purged DMF for reduction (a) or acetonitrile for oxidation (b) using $0.1 \mathrm{M} \mathrm{n}-\mathrm{Bu}_{4} \mathrm{NClO}_{4}$ as electrolyte. Scan rate: $0.1 \mathrm{~V} \cdot \mathrm{s}^{-1}$

\section{Photocycloreversion}

The photocycloreversion of cyclobutane thymine dimers in the presence of compounds acting as oxidants or reductants in their excited states has been largely reported in the literature (see for example refs $[11,14]$. By contrast, ring opening of $A Z T_{m}$ to regenerate the native dyad $\mathrm{azaU}_{\mathrm{m}}-\mathrm{T}_{\mathrm{m}}$ has only been achieved in the presence of electron donors, such as $N, N, N^{\prime}, N^{\prime}$-tetramethyl1,4-phenylenediamine. ${ }^{[4 c]}$ Hence, photooxidation of $A Z T_{m}$ was attempted in the presence of DCN as the electron acceptor and analyzed by HPLC to determine the obtained photoproducts. A deaerated acetonitrile solution of $A Z T_{m}(1.5 \mathrm{mM})$ was irradiated at $330 \mathrm{~nm}$ in the presence of DCN (4 mM) for $100 \mathrm{~min}$. As shown in Figure 3 , under these conditions the azetidine was split giving rise to the dyad azaU $\bigcup_{m}-T_{m}$. By contrast with the photoreductive version of the reaction, ${ }^{[4 c]}$ a quantitative formation of $a z a U_{m}-T_{m}$ was not observed (Figure 3, inset). This can be attributed to further oxidation of the nucleobases by DCN leading to the formation of secondary products. Indeed, a similar behavior has been described in the literature for the photocycloreversion of cyclobutane thymine (and cytosine) dimers in the presence of electron acceptors. ${ }^{[14 a]}$

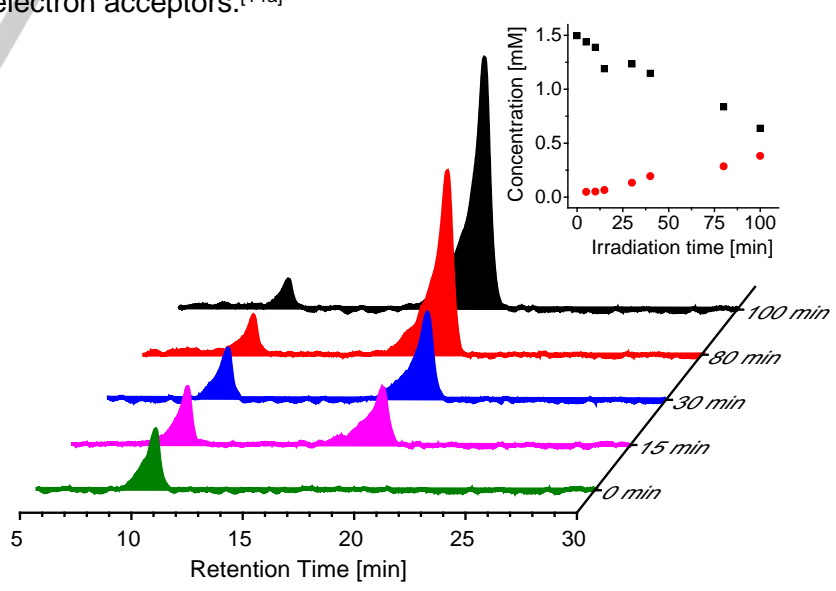

Figure 3. HPLC chromatograms, monitored at $\lambda=220 \mathrm{~nm}$, of the photooxidative cycloreversion of $A Z T_{m}$ (at retention time of ca. $10 \mathrm{~min}$ ) and $\mathrm{azaU}_{\mathrm{m}}-\mathrm{T}_{\mathrm{m}}$ (at retention time of ca. $20 \mathrm{~min}$ ) in the presence of $\mathrm{DCN}$ under monochromatic irradiation at $330 \mathrm{~nm}$. Inset: Time course of the photoreaction (AZTm, black squares and $\mathrm{azaU}_{\mathrm{m}}-\mathrm{T}_{\mathrm{m}}$ red points). 


\section{Quantum-chemistry determination of the photoreductive and photooxidative properties}

To gain insight into the energetics involved in the injection and removal of one electron in the azetidine and cyclobutane derivatives, the ionization potentials (IPs) and electron affinities (EAs), respectively, were computed for the $N$-demethylated compounds AZT and $\mathrm{T}<>\mathrm{T}$ with the density functional theory (DFT) method, the M06-2X functional and the $6-31++G(d, p)$ basis set. Benchmark calculations (Table S1) on the thymine nucleobase compared with high-level complete-active-space selfconsistent field second-order perturbation theory (CASPT2) results indicate an accurate performance of the DFT/M06-2X method for the vertical and adiabatic IPS (VIPS and AIPS) and adiabatic EAs (AEAs). Vertical EAs (VEAs) involve temporary anion states much more difficult to describe (see Refs. ${ }^{[15]}$ for more details). Hence, we keep them out of the analysis. Table 2 compiles the computed gas phase and acetonitrile solution values, which also allows an estimation of the solvent effect. As expected, solvation has an important influence on the IP and EA values because it stabilizes to a higher extent the ionic states as compared to the neutral state. Regarding IPs, Table 2 shows significantly lower IPs values for AZT than for T<>T, while EAs differ only slightly. This allows us to interpret the fact that higher experimental quenching rates $\left(\mathrm{k}_{\mathrm{q}}\right)$ were measured for $\mathrm{AZT_{m }}$ than for $T_{m}<>T_{m}$ in the case of photooxidants (DCN and DCA) while similar $k_{q}$ values were obtained for the photoreduction (see Table 1).

Table 2. Vertical ( $\mathrm{V}$ ) and adiabatic (A) ionization potentials (IPS) and electron affinities (EAs) in $\mathrm{eV}$ ( $\mathrm{kcal} \mathrm{mol}^{-1}$ within parentheses) for AZT and $\mathrm{T}<>\mathrm{T}$ in the gas phase and in acetonitrile computed with the DFT/M06-2X method and the $6-31++G(d, p)$ basis set.

\begin{tabular}{lccc}
\hline & VIP & AIP & AEA \\
\hline AZT & & & \\
Gas phase & $9.02(207.9)$ & $8.06(185.8)$ & $0.50(11.6)$ \\
Acetonitrile & $7.14(164.7)$ & $6.23(143.7)$ & $2.16(49.9)$ \\
T<>T & & & \\
Gas phase & $9.30(214.5)$ & $8.64(199.2)$ & $0.31(7.1)$ \\
Acetonitrile & $7.57(174.6)$ & $6.92(159.6)$ & $2.00(46.1)$ \\
\hline
\end{tabular}

To interpret the excited-state quenching of photosensitizers (Phs) by $A Z T_{m}$, four Phs with significantly different redox properties of the singlet excited state were chosen to carry out a quantumchemistry determination of the photoreduction and photooxidation energetics: 1-MN and DCN (used in the experiments detailed above), together with $\quad N, N, N^{\prime}, N^{\prime}$-tetramethyl-1,4phenylenediamine (TMPD) and cyanonaphthalene (CNN), employed in previous works. ${ }^{[4 c, 4 d]}$ Singlet-excited-state redox potentials were $\mathrm{E}^{\star}$ of $-2.5,2.4,-3.3$, and $1.4 \mathrm{~V}$ vs. $\mathrm{Ag} / \mathrm{AgCl}$, respectively. By using the time-dependent (TD)-DFT method, the electronic band origins (or adiabatic electronic-transition energies) of the lowest-lying excited state of the Phs ( $\left.E_{S 1}\right)$ were computed. Such information together with the AIP and AEA values of AZT, compiled in Table 2, allowed to determine the energy difference $\left(\triangle \mathrm{E}_{\text {redox }}\right)$ related to the photoreduction $\left(\mathrm{Phs}^{*}+\right.$ $\left.\mathrm{AZT} \rightarrow \mathrm{Phs}^{\bullet+}+\mathrm{AZT}^{\bullet-}\right)$ and photooxidation $\left(\mathrm{Phs}^{*}+\mathrm{AZT} \rightarrow \mathrm{Phs}^{\bullet-}\right.$
$+\mathrm{AZT}^{\bullet+}$ ) processes (see Table 3). Data related to 1-MN and DCN will allow us to establish theory-experiment comparisons, whereas those values computed for TMPD and CNN shall provide with new information not obtained in the experiments. Indeed, for TMPD, the experimental $k_{q}$ could not be determined in the previous work ${ }^{[4 c]}$ due to the temporal resolution of the setup and for CNN no quenching is observed in the present study. According to the computed $\Delta \mathrm{E}_{\text {redox }}$ values, TMPD was found to have the strongest photoreduction ability. In the photooxidation process exerted by $C N N, \Delta E_{\text {redox }}$ is very close to zero. This might explain the fact that attempts to experimentally measure $\mathrm{k}_{\mathrm{q}}$ for this Phs in this work were not successful. As it can be seen in Table 1 and 3, DCN and 1-MN have intermediate photooxidation and photoreduction properties, respectively. Theory (Table 3) predicts here a more favorable process for DCN than for 1-MN, which is in agreement with the experimental $\mathrm{k}_{\mathrm{q}}$ data compiled in Table 1.

Decomposition mechanisms of AZT radical anion and cation The reduction of AZT produces the rupture of the C-C bond due to the fact that the anion of the four-membered ring is not a stable structure (see Figure 4). The extra electron from the photosensitizer is partially located in the $\sigma^{\star}$ orbital of the $\mathrm{C}-\mathrm{C}$ bond thus weakening this bond, which breaks. For $\mathrm{T}<>\mathrm{T}$, previous studies (see, for instance, Ref. ${ }^{[16]}$ ) and the current work also indicate a more favorable open structure for the anion.

Table 3. Adiabatic absorption energy of the lowest-lying singlet excited state $\left(E_{S 1}\right)$, adiabatic ionization potentials or electron affinities (AIP/AEA) of the selected photosensitizers and energy change $\left(\Delta \mathrm{E}_{\text {redox }}\right)$ related to the photoreduction $\left(\mathrm{PhS}_{\mathrm{red}}{ }^{*}+\mathrm{AZT} \rightarrow \mathrm{PhS}_{\mathrm{red}}{ }^{\bullet+}+\mathrm{AZT}^{\bullet-}\right.$ ) or photooxidation (Phsox ${ }^{*}+$ $\mathrm{AZT} \rightarrow \mathrm{Phsox}^{\bullet-}+\mathrm{AZT}^{\bullet+}$ ) processes in $\mathrm{eV}\left(\mathrm{kcal} \mathrm{mol}^{-1}\right.$ within parentheses) computed in solution (acetonitrile) with the DFT/M06-2X method, the 6$31++G(d, p)$ basis set and the PCM approach.

\begin{tabular}{lccc}
\hline & $\mathrm{E}_{\mathrm{S} 1}$ & AIP/AEA & \multicolumn{1}{c}{$\Delta \mathrm{E}_{\text {redox }}$} \\
\hline Photoreduction & & & \\
TMPD & $3.72(85.8)$ & $4.53(104.5)^{[\mathrm{a}]}$ & $-1.35(-31.1)$ \\
1-MN & $4.07(93.8)$ & $5.91(136.3)^{[\mathrm{a}]}$ & $-0.32(-7.4)$ \\
Photooxidation & & & \\
DCN & $3.62(83.5)$ & $3.14(72.4)^{[\mathrm{b}]}$ & $-0.53(-12.2)$ \\
CNN & $3.95(91.1)$ & $2.43(56.0)^{[\mathrm{b}]}$ & $-0.15(-3.4)$ \\
\hline
\end{tabular}

[a] Adiabatic ionization potential. [b] Adiabatic electron affinities.

Evolution of the system towards recovery of the thymine and 6azauracil molecules has also been studied with appropriate reaction path computational strategies showing an electronic energy barrier height of around $13 \mathrm{kcal} \mathrm{mol}^{-1}$ (see Figure 5). Due to technical difficulties to accurately determine the TS structure, an approximated procedure has been used. This approach, based on minimum energy path (MEP) and linear interpolation of internal coordinates (LIIC) calculations, gives rise to a connected path between reactant and product and provides an upper-bound value for the barrier. Therefore, the exact energy barrier height shall be expected at slightly lower energies in the range of 10-13 $\mathrm{kcal} \mathrm{mol}^{-1}$. Regarding the electronic-structure properties, analysis of the spin density obtained with the complete-active space selfconsistent field (CASSCF) method indicates a delocalization of the extra electron over the two carbon atoms which breaks at the 
reactant side of the cycloreversion mechanism (see Figures 6 and S3). Once the two monomers are regenerated, the unpaired electron is localized in 6-azauracil.

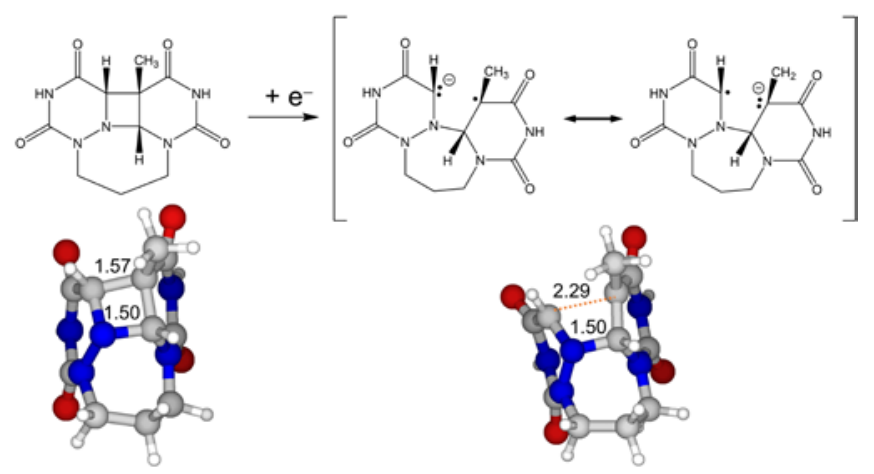

Figure 4. Chemical structures (top) and geometries (bottom) of the neutral AZT (left) and its radical anion $\mathrm{AZT} \mathrm{T}^{\bullet-}$ (right). Relevant bond distances for the reaction are shown in $\AA$.
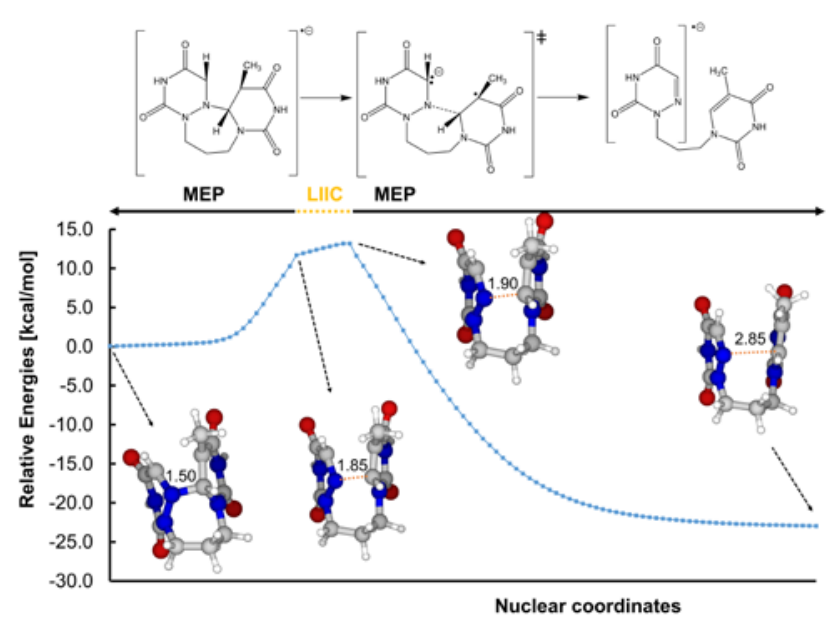

Figure 5. Chemical structure of relevant points (top) and energy profile (bottom) for the $\mathrm{C}-\mathrm{N}$ and $\mathrm{C}-\mathrm{C}$ bond breakings of $\mathrm{AZT}$ radical anion (AZT ${ }^{\circ}$ ) obtained with minimum energy path (MEP) and linear interpolation of internal coordinates (LIIC) computational strategies. Relevant bond distances for the reaction are shown in $\AA$.

For the photooxidation, the 4-membered ring is preserved in the cationic structure, in contrast to the findings obtained for the corresponding anion. The reaction mechanism of $\mathrm{AZT}^{\bullet+}$ implies an asynchronous $\mathrm{N}-\mathrm{C}$ and $\mathrm{C}-\mathrm{C}$ bond breaking, in which the first cleavage $(\mathrm{N}-\mathrm{C})$ requires ca. $7.5 \mathrm{kcal} \mathrm{mol}^{-1}$ and gives rise to a relatively flat energy profile with no stable structure (see Figure 7). In such region, the carbon atom of the broken bond becomes a carbocation.

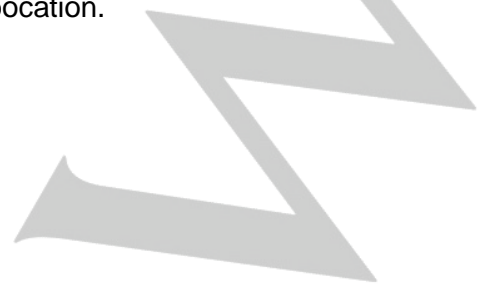

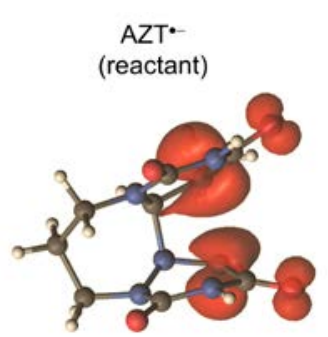

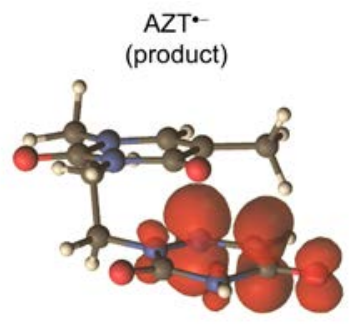

AZT*+

(reactant)
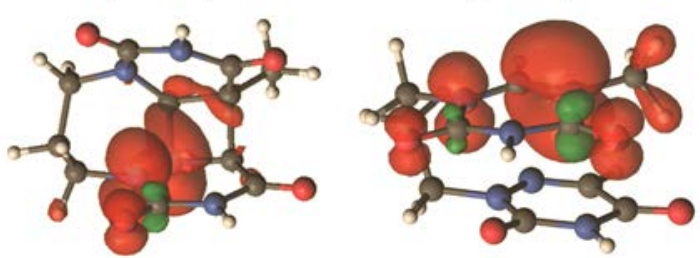

Figure 6. CASSCF spin-density representations for the AZT radical anion (top) and cation (bottom) systems at the reactant (left) and product (right) geometries, respectively. Red = excess of spin density, green = defect of spin density.

It can be seen in the gas-phase CASSCF spin-density representations of Figure 6 that the unpaired electron is localized over the nitrogen atom and to some extent also over the adjacent nitrogen atom. Similar findings are obtained by analyzing the M06-2X singly-occupied molecular orbital both in the gas phase and in acetonitrile (see Figure S3). The second step in the mechanism corresponds to the $\mathrm{C}-\mathrm{C}$ bond breaking and increases the energy barrier for the overall process up to $12.5 \mathrm{kcal} \mathrm{mol}^{-1}$.

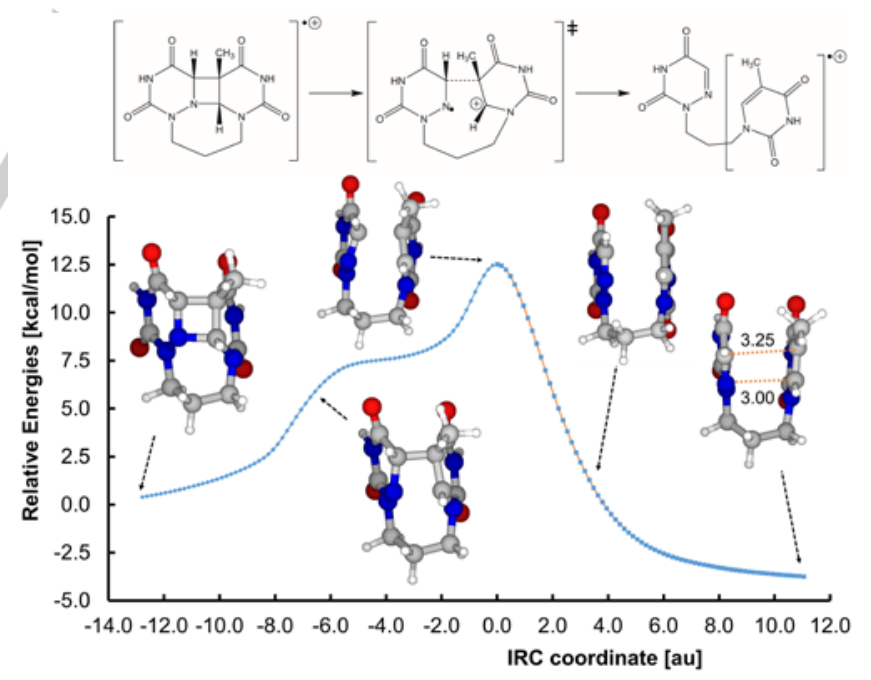

Figure 7. Chemical structure of relevant points (top) and energy profile (bottom) for the $\mathrm{C}-\mathrm{N}$ and $\mathrm{C}-\mathrm{C}$ bond breakings of $\mathrm{AZT}$ cation $\left(\mathrm{AZT}^{\bullet+}\right)$ obtained with intrinsic reaction path (IRC) computational strategy. Relevant bond distances for the reaction are shown in $\AA$.

Globally, the in-vacuo mechanism described above implies energy barriers lower than $13 \mathrm{kcal} \mathrm{mol}^{-1}$ for both the radical anion and cation systems. The cycloreversion process is clearly 
exergonic for $\mathrm{AZT}^{\bullet-}$ whereas a much lower energy release is determined for $\mathrm{AZT}^{\bullet+}$. To further improve the description, we have focused on the relevant points for the present mechanism (reactants, TSs and products) and we have determined several thermochemical magnitudes using the highly accurate CASPT2 method. In particular, the activation energy $\left(\Delta \mathrm{E}^{\#}\right)$ and thermodynamics $(\Delta E)$, the zero-point vibrational energy (ZPVE) corrected values $\left(\Delta \mathrm{E}_{0}^{\#}\right.$ and $\left.\Delta \mathrm{E}_{0}\right)$ and the Gibbs free energies $\left(\Delta \mathrm{G}^{\#}\right.$ and $\Delta \mathrm{G}$ ) have been computed at both gas and solution phases. Results are compiled in Table 4. As it can be seen, the CASPT2 method confirms the relatively low DFT energy barrier heights and the highly exergonic character of the $\mathrm{AZT}^{\bullet-}$ ring opening reaction. For $\mathrm{AZT}^{\bullet+}$, both methods differ in the sign of $\Delta \mathrm{E}$; however, the values are around zero. Regarding the solvent effects, in contrast to the redox properties determined in the previous section, no significant changes are observed for the $\mathrm{AZT}^{\bullet-}$ and $\mathrm{AZT}^{\bullet+}$ cycloreversion mechanisms. This is due to the fact that along the ring opening reactions the total charge is preserved. The ZPVE correction gives rise to lower $\Delta \mathrm{Es}$ as a consequence of the bond breakings occurring along the reactions. The same behavior is observed for $\Delta \mathrm{G}$, which reflects the entropy increase in the decomposition process.

Table 4. Computed energy differences between products and the reactants ( $\Delta \mathrm{E}$, $\Delta \mathrm{E}_{0}$ and $\left.\Delta \mathrm{G}\right)$ and activation energies $\left(\Delta \mathrm{E}^{\ddagger}, \Delta \mathrm{E}_{0^{\ddagger}}\right.$ and $\left.\Delta \mathrm{G}^{\ddagger}\right)$ for the cycloreversion of the AZT radical anion and cation. Energies in $\mathrm{kcal} \mathrm{mol}^{-1}$.

\begin{tabular}{|c|c|c|c|c|}
\hline \multirow[t]{2}{*}{ Methodology } & \multicolumn{2}{|c|}{$A Z T^{\bullet}$} & \multicolumn{2}{|c|}{$\mathrm{AZT}^{\bullet+}$} \\
\hline & $\Delta \mathrm{E}^{[\mathrm{a}]}$ & $\Delta \mathrm{E}^{\ddagger}$ & $\Delta \mathrm{E}^{[\mathrm{a}]}$ & $\Delta \mathrm{E}^{\ddagger}$ \\
\hline M06-2X & $-29.07^{[b]}$ & $11.69-13.20^{[\mathrm{b}]}$ & $-4.89^{[b]}$ & $12.52^{[\mathrm{b}]}$ \\
\hline CASPT2//M06-2X & $-25.16^{[b]}$ & $11.88-12.85^{[\mathrm{b}]}$ & $2.21^{[b]}$ & $14.77^{[\mathrm{b}]}$ \\
\hline \multirow[t]{2}{*}{ PCM-M06-2X } & $-29.20^{[c]}$ & $11.22-12.51^{[\mathrm{c}]}$ & $-3.09^{[c]}$ & $13.52^{[c]}$ \\
\hline & $\Delta \mathrm{E}_{0}$ & $\Delta \mathrm{E}_{0^{\ddagger}}$ & $\Delta \mathrm{E}_{0}$ & $\Delta \mathrm{E}_{0^{\ddagger}}$ \\
\hline M06-2X & $-29.87^{[\mathrm{d}]}$ & _[e] & $-7.36^{[\mathrm{d}]}$ & $10.73^{[d]}$ \\
\hline \multirow[t]{2}{*}{ CASPT2//M06-2X } & $-25.96^{[\mathrm{d}]}$ & -[e] & $-0.26^{[\mathrm{d}]}$ & $12.98^{[\mathrm{d}]}$ \\
\hline & $\Delta \mathrm{G}$ & $\Delta \mathrm{G}^{*}$ & $\Delta \mathrm{G}$ & $\Delta \mathrm{G}^{*}$ \\
\hline M06-2X & $-30,99^{[f]}$ & -[e] & $-8.99^{[f]}$ & $11.47^{[f]}$ \\
\hline CASPT2//M06-2X & $-27.08^{[f]}$ & [e] & $-1.89^{[f]}$ & $13.72^{[f]}$ \\
\hline
\end{tabular}

[a] Energies related to the lowest-energy conformer of the product (see text). [b] Electronic energy (gas phase). [c] Electronic energy including solvent effects (acetonitrile). [d] Electronic energy with ZPVE corrections (gas phase).

[e] No TS found. [f] Electronic energy with thermal and entropic contributions at 298.15 K and $1 \mathrm{~atm}$ (gas phase).

Finally, Table 5 compares the overall ability $\left(\Delta \mathrm{E}_{\mathrm{pc}}^{\neq}\right)$of the different photosensitizers to produce the photoinduced cycloreversion of AZT. Upon excitation of TMPD, the reduction process releases a much larger amount of energy as compared to the barrier needed to break the bonds between the thymine and 6-azauracil units. Thus, TMPD is the best Phs and DCN continues the trend. In the latter case, the Phs oxidizes the AZT dimer given the very small energy barrier. Such activation energy increases in 1-MN and especially in CNN. Since the barrier heights for the ring opening of $\mathrm{AZT}^{\bullet-}$ and $\mathrm{AZT}^{\bullet+}$ are similar, the efficiency of the Phs to trigger the cycloreversion of $A Z T$ is basically determined by the excitedstate redox properties of such sensitizers. Therefore, the trends observed in the overall process (Table 5) show a good correlation with the observed quenching rates measured in the experiments and compiled in Table 1. As already mentioned above, experiments with CNN have not shown any quenching in contrast to the others. This agrees with the higher energy barrier obtained for this Phs.

Table 5. Computed gas-phase overall energy barrier height $\left(\Delta \mathrm{E}_{\mathrm{pc}}^{\neq}\right)$for the photoreductive ring opening $\mathrm{Phs}_{\mathrm{red}}{ }^{*}+\mathrm{AZT} \rightarrow \mathrm{Phs}_{\mathrm{red}}{ }^{\bullet+}+\mathrm{azaU}^{-\mathrm{T}^{*-}}$ and the photooxidative ring opening $\mathrm{PhS}_{\mathrm{ox}}{ }^{*}+\mathrm{AZT} \rightarrow \mathrm{PhS}_{\mathrm{ox}}{ }^{\bullet+}+$ azaU- $\mathrm{T}^{\bullet-}$, with $\mathrm{PhS}_{\text {red }}=$ TMPD, 1-MN and $\mathrm{PhS}_{\mathrm{ox}}=\mathrm{DCN}, \mathrm{CNN}$. Energies in $\mathrm{kcal} \mathrm{mol}^{-1}$.

\begin{tabular}{lc} 
& $\Delta \mathrm{E}_{\mathrm{pc}}^{\ddagger}$ \\
\cline { 2 - 2 } $\mathrm{TMPD}$ & $-19.41--17.90$ \\
$\mathrm{DCN}$ & 0.32 \\
$1-\mathrm{MN}$ & $4.29-5.80$ \\
$\mathrm{CNN}$ & 9.12 \\
\hline
\end{tabular}

\section{Conclusions}

The photooxidative and photoreductive cycloreversion of an azabipyrimidinic azetidine ( $A Z \mathrm{~T}_{\mathrm{m}}$ ) have been addressed through a multifaceted approach including spectroscopic, electrochemical and analytical experiments complemented by theoretical calculations. In a first stage, the electron accepting and donating capabilities of this 4-membered heterocycle have been established by means of singlet excited state quenching. In this context, comparison of the bimolecular rate constants obtained for $A Z T_{m}$ with those of a cyclobutane derivative $T_{m}<>T_{m}$ has revealed that the presence of the nitrogen atom in the ring facilitates its oxidation, while comparable behavior has been observed for the reduction process. The electrochemical experiments fully support these redox features as close reduction peaks have been registered for $A Z T_{m}$ and $T_{m}<>T_{m}$, a result that contrasts with their oxidation waves differing in ca. $0.5 \mathrm{~V}$. Quantum-chemistry determinations based on DFT and CASSCF/CASPT2 methodologies have allowed to interpret the observations. Furthermore, the ring-opening mechanisms have also been analyzed by the theoretical methods. The azetidine radical anion spontaneously dissociates the $\mathrm{C}-\mathrm{N}$ bond of the fourmembered ring upon electron attachment after photoreduction. Subsequently, the $\mathrm{C}-\mathrm{C}$ bond breaking step requires an activation energy lower than $13 \mathrm{kcal} \mathrm{mol}^{-1}$ and is significantly exergonic. Meanwhile, cycloreversion of the azetidine radical cation produced in the photooxidation is characterized by asynchronous $\mathrm{C}-\mathrm{N}$ and $\mathrm{C}-\mathrm{C}$ bond ruptures with an overall energy barrier also lower than $13 \mathrm{kcal} \mathrm{mol}^{-1}$ although it is much less exergonic. Altogether, these experimental and theoretical findings represent an important advance in the understanding of photoinduced cycloreversion of azetidines by electron transfer.

\section{Experimental Section}

Chemicals. Dimethylformamide (Fisher, extra dry over molecular sieves), anhydrous acetonitrile and the supporting electrolyte $\mathrm{Bu}_{4} \mathrm{NClO}_{4}$ (abcr) were used as received. Dyads $A Z T_{m}, a z a U_{m}-T_{m}$, and $T_{m}<>T_{m}$ were 
synthesized as previously described, the N3-methylated derivatives were used to allow a higher solubility in organic media. ${ }^{[4 c, 17]}$

UV-Vis absorption. Absorption spectra were registered on a Cary 60 using quartz cuvettes of $1 \mathrm{~cm}$ of optical path.

Steady-state fluorescence. Steady-state fluorescence experiments were carried out on a Photon Technology International (PTI) LPS-220B spectrofluorometer. All experiments were performed under air in a quartz cuvette of $1 \mathrm{~cm}$ of optical path. The absorbance of the sensitizer for the fluorescence experiments was kept under 0.15 at the excitation wavelength ( $\lambda_{\text {exc }}=310 \mathrm{~nm}$ for DCN, $375 \mathrm{~nm}$ for DCA, $290 \mathrm{~nm}$ for 1-MN and $266 \mathrm{~nm}$ for CHRY). Stock solutions of the quenchers (AZT $T_{m}$ or $T_{m}<>T_{m}$ $0.15 \mathrm{M}$ ) were prepared, so it was only necessary to add microliter volumes to the sample cell to obtain appropriate concentrations of the quencher. The bimolecular rate constants $\mathrm{k}_{\mathrm{q}}(\mathrm{SS})$ for the reaction were obtained from the Stern-Volmer plots following the equation:

$\mathrm{I} / \mathrm{l}=1+\mathrm{kq}_{\mathrm{q}}(\mathrm{SS}) \tau_{0}[\mathrm{Q}]=1+\mathrm{Ksv}[\mathrm{Q}]$

where $I_{0}$ and $I$ are the emission intensity in the absence of $Q$ and after the addition of a quencher concentration [Q], respectively; $\mathrm{K}_{\mathrm{Sv}}\left(=\mathrm{k}_{\mathrm{q}}(\mathrm{SS}) \tau_{0}\right)$ the Stern-Volmer rate constant obtained from the slope and $\tau_{0}$ is the lifetime of the photosensitizer in the absence of $\mathrm{Q}$.

Time-resolved fluorescence. Measurements were performed with a EasyLife $V$ spectrometer from OBB, equipped with a pulsed LED as excitation source; residual excitation signal was filtered in emission by using a cut-off filter. The kinetic traces were fitted by one monoexponential decay function, using a deconvolution procedure to separate them from the lamp pulse profile.

The absorbance of the sensitizer for the fluorescence experiments was kept at 0.15 at the excitation wavelength $\left(\lambda_{\text {exc }}=310 \mathrm{~nm}\right.$ for DCN, $375 \mathrm{~nm}$ for DCA, $295 \mathrm{~nm}$ for 1-MN, $310 \mathrm{~nm}$ for CHRY) Quenchers stock solutions of $0.15 \mathrm{M}$ (ie. $A Z T_{m}$ or $T_{m}<>T_{m}$ ) were also used for this experiment, and the rate constants $\mathrm{kq}_{\mathrm{q}}(\mathrm{TR})$ for the reaction were obtained from the SternVolmer plots following the equation:

$1 / \tau=1 / \tau_{0}+k_{\mathrm{q}}(\mathrm{TR})[\mathrm{Q}]$

where $\tau_{0}$ is the lifetime of the photosensitizer in the absence of $Q$ and $\tau$ is the lifetime after addition of a quencher concentration [Q].

HPLC measurements. The irradiated solutions were analyzed by HPLC using reversed phase column (MEDITERRANEA SEA $18,25 \times 0.46 \mathrm{~cm}, 5 \mu$ Teknokroma). A mixture of $20 / 80 \mathrm{CH}_{3} \mathrm{CN} / \mathrm{H}_{2} \mathrm{O}$ v/v at a flow of $1 \mathrm{~mL} \mathrm{~min}{ }^{-1}$ was used as mobile phase. Consumption of $A Z T_{m}$ and formation of $\mathrm{azaU}_{\mathrm{m}-}$ $\mathrm{T}_{\mathrm{m}}$ was monitored using a PDA detector set at 220 and $270 \mathrm{~nm}$, respectively; and areas of their peaks were correlated to calibration curves derived from authentic samples $a^{2} \mathrm{U}_{\mathrm{m}}-T_{\mathrm{m}}$ and $A Z T_{\mathrm{m}}$ allowing the determination of their concentration as a function of irradiation time.

Cyclic voltammetry. Cyclic voltammetry measurements were performed with a VersaSTAT 3 potentiostat (Princeton Applied Research, AlgeteMadrid, Spain) and using a three electrode standard configuration with glassy carbon as working electrode, platinum wire as counter electrode, and $\mathrm{Ag} / \mathrm{AgCl}$ in $3 \mathrm{M} \mathrm{NaCl}$ as reference electrode. Measurements were carried out on $\mathrm{N}_{2}$-purged acetonitrile (for oxidation) or dimethylformamide (for reduction) solutions of $A Z T_{m}, T_{m}<>T_{m}$, and 1,3-dimethyl-6-azauracil (2 $\mathrm{mM}$ ) with $0.1 \mathrm{M} \mathrm{Bu}_{4} \mathrm{NClO}_{4}$ as electrolyte at a scan rate of $0.1 \mathrm{~V} \mathrm{~s}^{-1}$. Ferrocene was taken as standard and measured potentials have been referenced to the $E_{1 / 2}$ potential of the ferrocinium/ferrocene $\left(\mathrm{Fc}^{+} / \mathrm{Fc}\right)$ couple of $0.425 \mathrm{~V}$ in $\mathrm{CH}_{3} \mathrm{CN} .{ }^{[18]}$

Quantum-chemistry ground-state computations. All geometry optimizations have been carried out employing the DFT method, in particular, making use of the Minnesota DFT/M06-2X hybrid functional[19] and the standard $6-31++G(d, p)$ basis set, as implemented in the GAUSSIAN 09 (D.01 revision) software package. ${ }^{[20]}$ This computational method provided satisfactory descriptions of the reactivity of other DNAbased open-shell and closed-shell systems. ${ }^{[21]}$ Frequency calculations using the harmonic oscillator approximation were used to obtain the ZPVEs and to verify the nature of the stationary points, by checking the absence of any imaginary frequency at the minima and the presence of only one imaginary vibrational mode (reaction coordinate) at the TS structure. For $\mathrm{AZT}^{\bullet+}$, IRC calculations have been performed to ensure the connectivity between the TS and the related minima. For the AZT ${ }^{\bullet-}$, the TS that leads to the $\mathrm{C}-\mathrm{N}$ bond breaking was not found since the reaction coordinate most probably depends on the bond stretching but also on a complex molecular reorganization of the relative orientations of the aromatic rings, as revealed by preliminar relaxed scan calculations. Therefore, MEP calculations starting from the two highest points of the relaxed scan potential energy surfaces (C-N distances of 1.85 and $1.90 \AA$, respectively) were conducted in order to connect both reactants and products and estimate in this way an upper bound for the energy barrier The energy of the mentioned molecular reorganization taking place between the two selected structures have been tracked by means of the LIIC procedure, which provides a connected (and therefore, possible) path between the two geometries, ensuring thereby the absence of any energy barrier not found by the relaxed scan exploration.

VIPs were computed by subtracting the energies of the neutral state to the energy of the cationic state at the equilibrium geometry of the former, whereas the AIPs were determined by subtracting the energy of the neutral state at its corresponding equilibrium geometries to the energy of the cationic state at its equilibrium geometry. On the other hand, the AEAs were obtained by subtracting the energy of the anionic state at its optimized geometry to the energy of the neutral state at its equilibrium geometry. Thereby, positive AEAs indicate stable anionic states, whereas positive VIPs and AIPs refer to unstable cations. Methylation at the N3 position of the thymine and the 6-azauracil units, which might affect in particular the ionization potentials and electron affinities, was considered by computing the VIPs, AIPs and AEAs of $A Z T_{m}$ in the gas phase and acetonitrile (see Table S2). Changes in general lower than $0.2 \mathrm{eV}$ were obtained, which does not affect the analysis and conclusions obtained in this work based on the AZT system (compare Tables 2 and S2). This further validates the $\mathrm{N}-\mathrm{H}$ model system used throughout in this study.

For the thermochemical properties, the rigid-harmonic oscillatorideal approximation has been used to estimate the Gibbs energies at $298.15 \mathrm{~K}$ and $1 \mathrm{~atm}$ to include the entropic effects. A previous benchmark of this approach reported reasonable accuracy at a modest computational cost. ${ }^{[22]}$ The influence of the solvent (acetonitrile) in the reaction energies was assessed by means of the PCM using the GAUSSIAN 09 default settings. The PCM-M06-2X method was applied on top of the converged M06-2X geometries.

The CASSCF method was used to build multiconfigurational ground-state wave functions on top of the M06-2X geometries. The active space has been chosen including the most relevant out-of-plane nitrogen lone pairs $\left(n_{N}\right), \pi$ and $\pi^{*}$ molecular orbitals of the 6-azauracil and thymine moieties in the azaU-T $\pi$-stacked arrangement, i.e. 12 electrons distributed into 12 molecular orbitals (12-in-12) for the neutral system. Thus, active spaces of (13-in-12) and (11-in-12) were used throughout to study the reactivity of the anionic and cationic systems, respectively. In the case of AZT $\bullet$ at the reactants structure, one $\pi$ and one $\pi^{\star}$ orbitals combine to produce the corresponding $\sigma$ and $\sigma^{*}$ orbitals of the C-N bond. Similarly, at the reactant structure of the AZT radical cation, two $\pi$ and two $\pi^{*}$ orbitals give rise to the two $\sigma / \sigma^{*}$ pairs of the $\mathrm{C}-\mathrm{N}$ and the $\mathrm{C}-\mathrm{C}$ covalent bonds.

$\mathrm{CASPT}^{[23]}$ as used to compute the dynamic electron correlation on top of the CASSCF wavefunction and thus provide accurate energies. An imaginary level shift of 0.2 a.u. was set in order to minimize the presence of weak intruder states. ${ }^{[24]}$ Regarding the ionization-potential electronaffinity (IPEA) parameter, ${ }^{[25]}$ the recommended value of 0.25 a.u. was used for the charged systems as previously benchmarked for cationic ${ }^{[26]}$ and anionic $^{[15]}$ DNA nucleobases, whereas the standard zeroth-order Hamiltonian (IPEA=0.0 a.u.) was employed for the neutral systems. All 
multiconfigurational calculations were performed with the MOLCAS 8 suite of programs ${ }^{[27]}$ and the atomic natural orbital (ANO) L-type basis set with the $\mathrm{C}, \mathrm{N}, \mathrm{O}[4 \mathrm{~s} 3 \mathrm{p} 1 \mathrm{~d}] / \mathrm{H}$ [2s1p] contraction scheme (ANO-L 431/21).[28]

Quantum-chemistry excited-states computations. Determination of the lowest-lying excited-state equilibrium structure in ACN and its energy related to the ground-state minimum in the Phs was carried out using timedependent TD-DFT and PCM approach, which is a standard and calibrated approach in fluorophores as those studied here. The $6-31++G(d, p)$ basis set was used and the calculations were carried out in the GAUSSIAN 09 (D.01 revision).

\section{Acknowledgements}

Spanish Government (CTQ2015-70164-P, CTQ2017-87054-C22-P, SVP-2013-068057 for A. B. F.-R. Grant and RYC-201519234 for D. R.-S. grant) and Valencia Regional Government (Prometeo/2017/075) are acknowledged for financial support. A.F.-M. is grateful to the Région Grand Est government (France) and the Université de Lorraine for their financial support.

Keywords: electron transfer • DNA damage • DNA Repair • CASPT2 - Density functional theory

\section{References:}

[1] a) D. Antermite, L. Degennaro, R. Luisi, Org. Biomol. Chem. 2017, 15, 34 50; b) N. Canu, P. Belin, R. Thai, I. Correia, O. Lequin, J. Seguin, M. Moutiez, M. Gondry, Angew. Chem. Int. Ed. 2018, 57, 3118-3122; c) F. Meyer, Chem. Commun. 2016, 52, 3077-3094; d) A. Brandi, S. Cicchi, F. M. Cordero, Chem. Rev. 2008, 108, 3988-4035; e) E. M. Carreira, T. C. Fessard, Chem. Rev. 2014, 114, 8257-8322; f) J. M. Lopchuk, K. Fjelbye, Y. Kawamata, L. R. Malins, C.-M. Pan, R. Gianatassio, J. Wang, L. Prieto, J. Bradow, T. A. Brandt, M. R. Collins, J. Elleraas, J. Ewanicki, W. Farrell, O. O. Fadeyi, G. M. Gallego, J. J. Mousseau, R. Oliver, N. W. Sach, J. K. Smith, J. E. Spangler, H. Zhu, J. Zhu, P. S. Baran, J. Am. Chem. Soc. 2017, 139, 3209-3226; g) A. Hameed, S. Javed, R. Noreen, T. Huma, S. Iqbal, H. Umbreen, T. Gulzar, T. Farooq, Molecules 2017, 22, 1691; h) V. Mehra, I. Lumb, A. Anand, V. Kumar, RSC Adv. 2017, 7, 45763-45783; i) E. Kumarasamy, S. K. Kandappa, R. Raghunathan, S. Jockusch, J. Sivaguru, Angew. Chem. Int. Ed. 2017, 56, 7056-7061; j) S. C. Schmid, I. A. Guzei, J. M. Schomaker, Angew. Chem. Int. Ed. 2017, 56, 12229-12233; k) S. Diethelm, E. M. Carreira, J. Am. Chem. Soc. 2015, 137, 6084-6096; l) A F. G. Glawar, S. F. Jenkinson, A. L. Thompson, S. Nakagawa, A. Kato, T. D. Butters, G. W. J. Fleet, ChemMedChem 2013, 8, 658-666; m) I Kagiyama, H. Kato, T. Nehira, J. C. Frisvad, D. H. Sherman, R. M. Williams, S. Tsukamoto, Angew. Chem. Int. Ed. 2016, 55, 1128-1132; n) N. Kato, E. Comer, T. Sakata-Kato, A. Sharma, M. Sharma, M. Maetani, J. Bastien, N. M. Brancucci, J. A. Bittker, V. Corey, D. Clarke, E. R. Derbyshire, G. L. Dornan, S. Duffy, S. Eckley, M. A. Itoe, K. M. J. Koolen, T. A. Lewis, P. S. Lui, A. K. Lukens, E. Lund, S. March, E. Meibalan, B. C. Meier, J. A. McPhail, B. Mitasev, E. L. Moss, M. Sayes, Y. Van Gessel, M. J. Wawer, T. Yoshinaga, A.-M. Zeeman, V. M. Avery, S. N. Bhatia, J. E. Burke, F. Catteruccia, J. C. Clardy, P. A. Clemons, K. J. Dechering, J. R. Duvall, M. A. Foley, F. Gusovsky, C. H. M. Kocken, M. Marti, M. L. Morningstar, B. Munoz, D. E. Neafsey, A. Sharma, E. A. Winzeler, D. F. Wirth, C. A. Scherer, S. L. Schreiber, Nature 2016, 538, 344.

[2] a) X. Wang, C. Liu, X. Zeng, X. Wang, X. Wang, Y. Hu, Org. Lett. 2017 19, 3378-3381; b) M. L. Sarazen, C. W. Jones, Macromolecules 2017, 50, 9135-9143.

[3] T. Schnitzer, H. Wennemers, J. Am. Chem. Soc. 2017, 139, 15356-15362.

[4] a) A. Kaiser, K. K. Mayer, A. Sellmer, W. Wiegrebe, Monatsh. Chem. 2003 134, 343-354; b) I. Andreu, J. Delgado, A. Espinós, R. Pérez-Ruiz, M. C. Jiménez, M. A. Miranda, Org. Lett. 2008, 10, 5207-5210; c) A. B. FragaTimiraos, V. Lhiaubet-Vallet, M. A. Miranda, Angew. Chem. Int. Ed. 2016 55, 6037-6040; d) A. B. Fraga-Timiraos, G. M. Rodríguez-Muñiz, V. Peiro-Penalba, M. A. Miranda, V. Lhiaubet-Vallet, Molecules 2016, 21 1683; e) R. Pérez-Ruiz, M. C. Jiménez, M. A. Miranda, Acc. Chem. Res.
2014, 47, 1359-1368; f) E. A. Leo, L. R. Domingo, M. A. Miranda, R. Tormos, J. Org. Chem. 2006, 71, 4439-4444.

[5] a) M. K. Cichon, S. Arnold, T. Carell, Angew. Chem. Int. Ed. 2002, 41, 767-770; b) G. Prakash, D. E. Falvey, J. Am. Chem. Soc. 1995, 117, 11375-11376; c) A. Joseph, D. E. Falvey, Photochem. Photobiol. Sci. 2002, 1, 632-635; d) J. Trzcionka, V. Lhiaubet-Vallet, C. Paris, N. Belmadoui, M. J. Climent, M. A. Miranda, ChemBioChem 2007, 8, 402-407; e) Q.-Q. Wu, Q.-H. Song, J. Phys. Chem. B 2010, 114, 9827-9832; f) R. Perez-Ruiz, S. Gil, M. A. Miranda, J. Org. Chem. 2005, 70, 1376-1381; g) R. PerezRuiz, M. A. Miranda, R. Alle, K. Meerholz, A. G. Griesbeck, Photochem. Photobiol. Sci. 2006, 5, 51-55; h) M. A. Izquierdo, L. R. Domingo, M. A. Miranda, J. Phys. Chem. A 2005, 109, 2602-2607; i) M. A. Miranda, M. A. Izquierdo, Chem. Commun. 2003, 364-365; j) M. A. Miranda, M. A Izquierdo, J. Am. Chem. Soc. 2002, 124, 6532-6533; k) R. Perez-Ruiz, J. A. Saez, L. R. Domingo, M. C. Jimenez, M. A. Miranda, Org. Lett. 2012, $14,5700-5703$.

[6] a) A. F. Glas, S. Schneider, M. J. Maul, U. Hennecke, T. Carell, Chem. Eur. J. 2009, 15, 10387-10396; b) M. J. Maul, T. R. M. Barends, A. F. Glas, M. J. Cryle, T. Domratcheva, S. Schneider, I. Schlichting, T. Carell, Angew. Chem. Int. Ed. 2008, 47, 10076-10080; c) S. Faraji, A. Dreuw, Photochem Photobiol. 2017, 93, 37-50; d) J. Yamamoto, P. Plaza, K. Brettel, Photochem. Photobiol. 2017, 93, 51-66; e) M. Zhang, L. Wang, D. Zhong, Photochem. Photobiol. 2017, 93, 78-92; f) S. Faraji, D. Zhong, A. Dreuw, Angew. Chem. Int. Ed. 2016, 55, 5175-5178.

[7] A. Sancar, Chem. Rev. 2003, 103, 2203-2238.

[8] J. Yamamoto, R. Martin, S. Iwai, P. Plaza, K. Brettel, Angew. Chem. Int. Ed. 2013, 52, 7432-7436.

[9] M. P. Scannell, D. J. Fenick, S.-R. Yeh, D. E. Falvey, J. Am. Chem. Soc 1997, 119, 1971-1977.

[10] S. R. Yeh, D. E. Falvey, J. Am. Chem. Soc. 1992, 114, 7313-7314.

[11] C. Pac, T. Ohtsuki, Y. Shiota, S. Yanagida, H. Sakurai, Bull. Chem. Soc. Jpn 1986, 59, 1133-1139.

[12] a) F. Boussicault, O. Kruger, M. Robert, U. Wille, Org. Biomol. Chem 2004, 2, 2742-2750; b) F. Boussicault, M. Robert, Chem. Rev. 2008, 108 2622-2645.

[13] G. Wenska, S. Paszyc, J. Photochem. Photobiol. B: Biol. 1990, 8, 27-37.

[14] a) D. J. Fenick, H. S. Carr, D. E. Falvey, J. Org. Chem. 1996, 60, 624-631; b) C. Pac, I. Miyamoto, Y. Masaki, S. Furusho, S. Yanagida, T. Ohno, A Yoshimura, Photochem. Photobiol. 1990, 52, 973-979; c) K. Van Nguyen, C. J. Burrows, J. Am. Chem. Soc. 2011, 133, 14586-14589; d) C. Behrens, T. Carell, Chem. Commun. 2003, 1632-1633; e) J.-R. Van Camp, T. Young, R. F. Hartman, S. D. Rose, Photochem. Photobiol. 1987, 45, 365-370.

[15] a) A. Francés-Monerris, J. Segarra-Martí, M. Merchán, D. Roca-Sanjuán, J. Chem. Phys. 2015, 143, 215101; b) I. González-Ramírez, J. SegarraMartí, L. Serrano-Andrés, M. Merchán, M. Rubio, D. Roca-Sanjuán, J. Chem. Theory Comput. 2012, 8, 2769-2776; c) D. Roca-Sanjuán, M. Merchán, L. Serrano-Andrés, M. Rubio, J. Chem. Phys. 2008, 129, 095104. B. Durbeej, L. A. Eriksson, J. Am. Chem. Soc. 2000, 122, 10126-10132. I. Aparici-Espert, G. Garcia-Lainez, I. Andreu, M. A. Miranda, V. Lhiaubet-Vallet, ACS Chem. Biol. 2018, 13, 542-547.

[18] V. V. Pavlishchuk, A. W. Addison, Inorg. Chim. Acta 2000, 298, 97-102. [19] Y. Zhao, D. G. Truhlar, Theor. Chem. Acc. 2008, 120, 215-241.

[20] M. J. Frisch, G. W. Trucks, H. B. Schlegel, G. E. Scuseria, M. A. Robb, J. R. Cheeseman, G. Scalmani, V. Barone, G. A. Petersson, H. Nakatsuji, X. Li, M. Caricato, A. Marenich, J. Bloino, R. Janesko, R. Gomperts, B. Menucci, H. P. Hratchian, J. V. Ortiz, A. F. Izmaylov, D. Sonnenberg, F. Williams-Young, F. Ding, F. Lipparini, F. Edigi, J. Goings, B. Peng, A Petrone, T. Henderson, D. Ranasinghe, V. G. Zakrzewski, J. Gao, N. Rega, W. Zheng, W. Liang, M. Hada, M. Ehara, K. Toyota, R. Fukuda, M. Hasegawa, T. Ishida, T. Nakajima, Y. Honda, O. Kitao, H. Nakai, T. Vreven, K. Throssell, M. J. J. A., J. E. Peralta, F. Ogliaro, M. Bearpark, J. J. Heyd, E. Brothers, K. N. Kudin, V. N. Staroverov, T. Keith, R. Kobayashi, J. Normand, K. Raghavachari, A. Rendell, J. C. Burant, S. S. Iyengar, J. Tomasi, M. Cossi, J. M. Millam, M. Klene, C. Adamo, R. Cammi, J. W. Ochterski, R. L. Martin, K. Morokuma, O. Farkas, J. B. Foresman, D. J. Fox, Wallingford CT, 2013.

[21] a) J. Aranda, A. Francés-Monerris, I. Tuñón, D. Roca-Sanjuán, J. Chem Theory Comput. 2017, 13, 5089-5096; b) A. Francés-Monerris, M. Merchán, D. Roca-Sanjuán, J. Phys. Chem. B 2014, 118, 2932-2939; c) A Francés-Monerris, M. Merchán, D. Roca-Sanjuán, J. Org. Chem. 2017, 82, 276-288.

[22] O. Isayev, L. Gorb, J. Leszczynski, J. Comput. Chem. 2007, 28, 1598-1609

[23] a) K. Andersson, P. A.. Malmqvist, B. O. Roos, J. Chem. Phys. 1992, 96, 1218-1226; b) D. Roca-Sanjuán, F. Aquilante, R. Lindh, WIREs Comput. Mol. Sci. 2012, 2, 585-603.

[24] N. Forsberg, P.-Å. Malmqvist, Chem. Phys. Lett. 1997, 274, 196-204.

[25] G. Ghigo, B. O. Roos, P.-Å. Malmqvist, Chem. Phys. Lett. 2004, 396, $142-$ 149.

[26] D. Roca-Sanjuán, M. Rubio, M. Merchán, L. Serrano-Andrés, J. Chem. Phys. 2006, 125, 084302. 


\section{FULL PAPER}

[27] F. Aquilante, J. Autschbach, R. K. Carlson, L. F. Chibotaru, M. G. Delcey,

L. De Vico, I. Fdez. Galván, N. Ferré, L. M. Frutos, L. Gagliardi, M. Garavelli, A. Giussani, C. E. Hoyer, G. Li Manni, H. Lischka, D. Ma, P. Å. Malmqvist, T. Müller, A. Nenov, M. Olivucci, T. B. Pedersen, D. Peng, F. Plasser, B. Pritchard, M. Reiher, I. Rivalta, I. Schapiro, J. Segarra - Martí, M. Stenrup, D. G. Truhlar, L. Ungur, A. Valentini, S. Vancoillie, V. Veryazov, V. P. Vysotskiy, O. Weingart, F. Zapata, R. Lindh, J. Comput. Chem. 2016, 37, 506-541.

[28] P.-O. Widmark, B. J. Persson, B. O. Roos, Theor. Chim. Acta 1991, 79,
419-432.
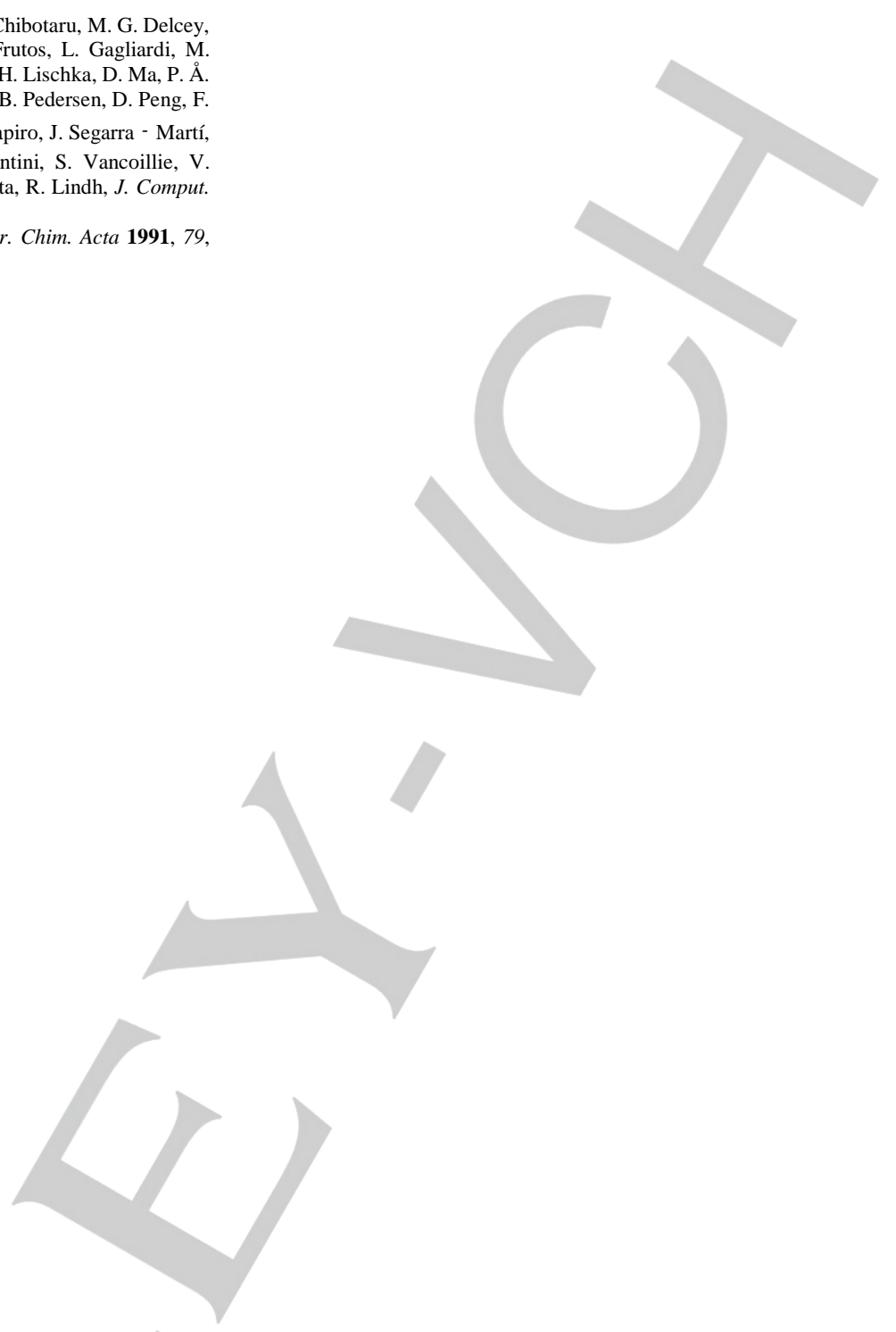
Entry for the Table of Contents (Please choose one layout)

Layout 2:

\section{FULL PAPER}

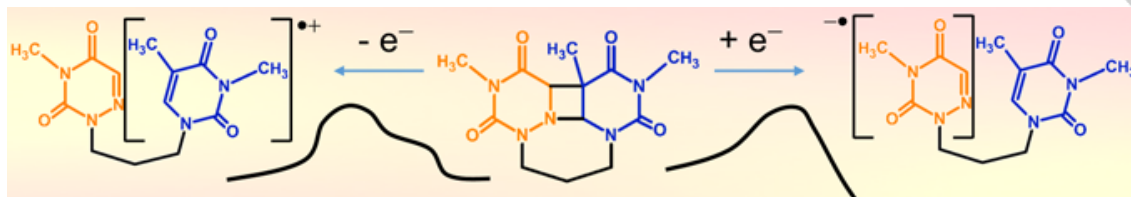

Product
Product
Photoinduced Electron Transfer
Ana B. Fraga-Timiraos, Antonio

Francés-Monerris, Gemma M.

Rodríguez-Muñiz, Miriam Navarrete-

Miguel, Miguel A. Miranda, Daniel Roca-

Sanjuán* and Virginie Lhiaubet-Vallet*

Page No. - Page No.

Experimental and Theoretical Study

on the Cycloreversion of a

Nucleobase-Derived Azetidine by

Photoinduced Electron Transfer

The ring-opening reaction of an azetidine derivative has been studied in detail using experimental and computational methodologies. Both photoinduced electron injection and abstraction lead to the cycloreversion of the heterocycle. 